\title{
Inflammatory cytokines and alpha-fetoprotein concentrations for predicting survival in patients with hepatocellular carcinoma
}

\author{
Xue Han ${ }^{1,2 \#}$, Yangkui Gu ${ }^{1,2 \#}$, Shaolong $\mathrm{Li}^{1}$, Minshan Chen ${ }^{1,3}$, Qingqing Cai ${ }^{1,4}$, Jinhua Huang ${ }^{1,2}$ \\ ${ }^{1}$ Sun Yat-sen University Cancer Center; State Key Laboratory of Oncology in South China; Collaborative Innovation Center for Cancer Medicine, \\ Guangzhou 510060, China; ${ }^{2}$ Department of Minimally Invasive Interventional Radiology, ${ }^{3}$ Department of Hepatobiliary Surgery, ${ }^{4}$ Department of \\ Medical Oncology, Sun Yat-sen University Cancer Center, Guangzhou 510060, China \\ Contributions: (I) Conception and design: J Huang, Q Cai, Y Gu; (II) Administrative support: J Huang, Q Cai; (III) Provision of study materials \\ or patients: X Han, Y Gu, M Chen; (IV) Collection and assembly of data: X Han, S Li; (V) Data analysis and interpretation: X Han, S Li; (VI) \\ Manuscript writing: All authors; (VII) Final approval of manuscript: All authors. \\ \#These authors contributed equally to the work. \\ Correspondence to: Jinhua Huang. Department of Minimally Invasive Interventional Radiology, Sun Yat-sen University Cancer Center, Guangzhou \\ 510060, China. Email: huangjh@sysucc.org.cn; Qingqing Cai. Department of Medical Oncology, Sun Yat-sen University Cancer Center, Guangzhou \\ 510060, China. Email: caiqq@sysucc.org.cn.
}

Background: Chronic inflammation is crucial in the evolution of hepatocellular carcinoma (HCC). Circulatory and intratumoral inflammatory factors are always increased in these patients. In this study, we determined the value of pretherapy serum concentrations of several inflammatory cytokines for predicting survival among patients with HCC.

Methods: We retrospectively analyzed data of 85 patients with HCC with known alpha-fetoprotein (AFP) concentrations diagnosed at our institute. Before therapy, serum concentrations of interleukin (IL)-2, -4, $-6,-10$, interferon gamma, and tumor necrosis factor alpha were measured by flow cytometry. Correlations between these serum factors and clinical parameters were tested. Statistical analysis was made by using non-parametric procedures and survival analysis. The expression of IL-6 and the co-expression of IL-6 and CD11b, marker of myeloid cell in HCC tumor tissues, were evaluated by immunohistochemistry and immunofluorescence, respectively.

Results: The only independent predictor of overall survival (OS) was IL-6 [hazard ratio (HR), 3.338; $95 \% \mathrm{CI}, 1.671$ to 6.666 ; $\mathrm{P}=0.001]$. OS was shorter among patients with high concentrations of both IL-6 $(\geq 1.435 \mathrm{pg} / \mathrm{mL})$ and AFP $(\geq 400 \mathrm{ng} / \mathrm{mL})$ than it was in those with high concentrations of either IL-6 or AFP; survival was significantly longer in patients with low concentrations of both markers $(\mathrm{P}<0.001)$. Immunostaining showed that IL-6 expression was localized to the stroma of the tumor and was co-expressed with CD11b positive cells.

Conclusions: The combination of serum concentrations of IL-6 and AFP more accurately predicts survival in HCC patients.

Keywords: Alpha-fetoprotein (AFP); interleukin 6; inflammatory factor; hepatocellular carcinoma (HCC); prognosis

Submitted Dec 19, 2018. Accepted for publication Jul 30, 2019.

doi: $10.21037 /$ tcr.2019.08.09

View this article at: http://dx.doi.org/10.21037/tcr.2019.08.09 


\section{Introduction}

Worldwide, primary hepatocellular carcinoma (HCC) is the fifth most common malignant tumor, and the second leading cause of cancer mortality in men and the sixth in women (1). The prognosis of patients with resectable HCC remains poor: more than $50 \%$ relapse within two years after resection (2). Staging systems, such as the Tumor, Node, Metastases (TNM) system, the Barcelona Clinic Liver Cancer (BCLC) system, and the Cancer of the Liver Italian Program (CLIP) score, are based on clinical characteristics that include tumor factors, general patient condition, and liver function, and are widely used to predict outcomes (3). However, although these characteristics provide adequate information to inform treatment decisions, they do not necessarily reflect the biological behavior of the tumor, and patients with tumors of the same stage may have different outcomes (4). Validated biomarkers would, therefore, be useful in complementing the limited prognostic ability of current staging systems.

Alpha-fetoprotein (AFP) is a specific tumor antigen secreted by hepatoma cells. A subclass of AFP-positive HCCs has been reported to have a unique gene expression signature and worse biological behaviour (5). Higher serum concentrations of AFP suggest more severe tumor invasion and a poorer prognosis (6). These findings indicate that AFP could be a prognostic biomarker because it may directly reflect features of HCC tumor biology. Considering the heterogeneous nature of HCC, complementary markers are needed to provide more general information.

Tumor-associated inflammation is a hallmark of cancer progression. Almost 70-90\% of HCC cases occur in the setting of chronic inflammation (7). Cytokines are essential components of the tumor microenvironment and participate in the intricate crosstalk between tumor cells and immune cells (8). Systemic inflammation predicts outcome in patients with surgically resectable HCC and in those patients with more advanced HCC (9). Elevated serum concentrations of various cytokines, including interleukin (IL)-2, IL-6, IL-8, IL-10, and IL-17, have been reported to be associated with prognosis in HCC patients (10-12). However, few cytokines have been independently validated as predictors of outcome.

In this study, we combined immune-related prognostic predictors screened from six tumor-immune-related cytokines with AFP and determined their ability to predict survival in patients with HCC.

\section{Methods}

\section{Patients, clinical specimens, and follow-up}

Patients were eligible for the study if, between December 2009 and December 2010, they had newly diagnosed HCC based on National Comprehensive Cancer Network guidelines, had no other malignancies or immune-related disease, had complete clinicopathologic and follow-up data until June 2018, a pre-treatment serum sample, and data on AFP concentrations.

Treatment for HCC patients was determined by our multidisciplinary team based on the BCLC staging system, including surgery, transcatheter arterial chemoembolization, and thermal ablation. Serum samples were collected from patients before treatment and stored at $-80{ }^{\circ} \mathrm{C}$ until processing. Surgically resected tumor specimens were fixed in formalin and embedded in paraffin for routine histologic diagnosis. Patients were followed until June 2018. Serum AFP concentrations were monitored, and liver computed tomography, or magnetic resonance imaging scans were obtained every two months during the first year after surgery and at least every four months after that. Independent physicians performed all examinations without knowledge of the current study. The primary endpoint was overall survival (OS), or the time to death from any cause measured from the date of surgery to the date of death or of last follow-up.

\section{Cytokine measurement}

The biomarkers IL-2, IL-4, IL-6, IL-10, interferon- $\gamma$ $(\mathrm{IFN}-\gamma)$, and tumor necrosis factor- $\alpha(\mathrm{TNF}-\alpha)$, were measured by a fluorescence-based detection system and flow cytometric analysis. Cytokines were captured on microparticles using a BD Cytometric Bead Array Human Th1/Th2 Cytokine kit (BD Biosciences, San Diego, CA, USA) according to the manufacturer's instructions. A series of diluted cytokine standards were run in each assay to generate standard curves. The samples were measured using a FACS Canto II (BD Biosciences, San Diego, CA, USA) and analyzed using FCAP array software (BD Biosciences, San Diego, CA, USA).

\section{Immunohistochemistry staining}

Formalin-fixed, paraffin-embedded tissue samples were 


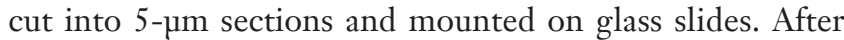
the sections were deparaffinized, rehydrated, and washed, endogenous peroxidase was blocked ( $3 \% \mathrm{H}_{2} \mathrm{O}_{2}$ for $10 \mathrm{~min}$ ), and microwave antigen retrieval was performed in TrisEDTA (pH 9.0). Sections were first incubated with blocking serum at room temperature for $30 \mathrm{~min}$ and then with mouse anti-IL-6 monoclonal antibody (1:8,000, ab9324; Abcam) at $4{ }^{\circ} \mathrm{C}$ overnight. The second incubation was done using goat anti-mouse antibody and visualized with DAB after counterstaining with hematoxylin after serial rinsing.

\section{Immunofuorescence staining}

Formalin-fixed, paraffin-embedded tissue samples were cut into 5 - $\mu \mathrm{m}$ sections and mounted on glass slides. After the sections were deparaffinized, rehydrated, and washed, microwave antigen retrieval was performed in Tris-EDTA ( $\mathrm{pH}$ 9.0). Sections were first incubated with blocking serum at room temperature for 30 min and with mouse anti-IL-6 monoclonal antibody $(1: 1,000$, ab9324; Abcam) combined with rabbit anti-CD11b monoclonal antibody (1:200, ab52478; Abcam) at $4{ }^{\circ} \mathrm{C}$ overnight. The second incubation was done using DyLight 488 AffiniPure goat anti-mouse IgG (1:100, E032210; EarthOx) and DyLight 594 AffiniPure goat anti-rabbit IgG (1:100, E032420; EarthOx) after counterstaining with DAPI and serial rinsing with $1 \times$ PBST.

\section{Statistical methods}

Data of cytokine concentrations are presented as means with standard deviations. Cut-off values for defining high and low values of each variable were determined by receiver operating characteristics analysis. Associations of the cytokine concentrations with clinical and pathologic features of the HCC patients were evaluated using MannWhitney U test or Kruskal-Wallis tests. Differences between categorical variables were analyzed with Chi-square tests. The correlation was assessed using the nonparametric Spearman's correlation.

Survival curves were analyzed with the Kaplan-Meier method and compared using log-rank tests with the following covariates: age $(\leq 50,>50$ years), sex (female, male), maximum tumor diameter $(\leq 50,>50 \mathrm{~mm})$, portal vein invasion (yes, no), hepatitis B virus (HBV) genomic DNA copy number $\left(<0.01 \times 10^{2}, \geq 0.01 \times 10^{2} \mathrm{IU} / \mathrm{mL}\right)$, hepatitis $\mathrm{B}$ (yes, no), BCLC stage (A, B and $\mathrm{C}$ ) and AFP concentration $(\leq 400,>400 \mathrm{ng} / \mathrm{mL})$. Concentrations of AFP above $400 \mathrm{ng} / \mathrm{mL}$ have been considered to be diagnostic for HCC in patients with cirrhosis [see the European Association for the Study of the Liver (EASL) guidelines] (13). Patients were divided into four groups based on low and high concentrations of AFP and IL-6 (AFP, $\leq 400$ vs. $>400 \mathrm{ng} / \mathrm{mL}$; IL-6, $\leq 1.435$ vs. $>1.435 \mathrm{ng} / \mathrm{mL})$. Covariates with $\mathrm{P}$ values less than 0.05 were then subsequently analyzed by multivariate time-to-event analysis using Cox proportional hazards regression. Alpha was set at 0.05 , and all tests were two-sided. Data were analyzed with GraphPad Prism 7.0 software (GraphPad Software, Inc., La Jolla, LA, USA) and the SPSS statistics package (version 19, SPSS Inc., Chicago, IL, USA).

\section{Results}

\section{Patient characteristics}

Out of 1,179 patients screened, 85 (78 men) met the inclusion criteria and were included in the study (Table 1). The mean age was 50 years. Out of 85 patients, 70 were in BCLC A stage, and 60 had hepatitis B virus (HBV)-related HCC. Median follow-up was 39.5 months (range, 2 to 103 months).

\section{Cytokine concentrations and clinical characteristics}

Pretreatment serum concentration cut-off values for predicting survival are shown in Table 2. Interleukin-6 concentrations differed significantly by maximum tumor diameters, portal vein invasion, and BCLC stage, while IL10 concentrations differed significantly by sex (Table 3). Concentrations of IL-6 also differed significantly between patients grouped by maximum tumor diameter analyzed as an ordinal variable with four categories (Figure 1).

\section{Survival analysis}

In the univariate analysis, maximum tumor diameter, AFP concentrations, BCLC stage, and IL-6 were significantly related to OS. Covariates with $\mathrm{P}$ values less than 0.05 were included in the multivariate analysis. AFP [hazard ratio (HR), 2.282; 95\% CI, 1.217 to 4.280; $\mathrm{P}=0.01$ ], BCLC stage (HR, 3.123; 95\% CI, 1.534 to $6.359 ; \mathrm{P}=0.002)$, and IL-6 concentrations (HR, 3.338; 95\% CI, 1.671 to 6.666 ; $\mathrm{P}=0.001)$ independently predicted survival, with cut-off values of $400 \mathrm{ng} / \mathrm{mL}$, BCLC stage $\mathrm{A}$, and $1.435 \mathrm{pg} / \mathrm{mL}$, respectively (Figure 2 and Table 4).

To combine the prognostic scores of IL-6 and AFP, we divided patients into four groups based on low and high 
Table 1 Clinical and tumor characteristics of 85 patients with hepatocellular carcinoma

\begin{tabular}{lc}
\hline Characteristics & $\mathrm{N}(\%)$ \\
\hline Sex & \\
Male & $78(91.8)$ \\
Female & $7(8.2)$ \\
Age & \\
$\leq 50$ & $41(48.2)$ \\
$>50$ & $44(51.8)$
\end{tabular}

Hepatitis B

Positive

Negative

$25(29.4)$

Alpha-fetoprotein, $\mathrm{ng} / \mathrm{mL}$

$\leq 400$

$>400$

$42(49.4)$

Maximum tumor diameter, $\mathrm{mm}$

30

$17(20.0)$

$>30$ to 50

$21(24.7)$

$>50$ to 100

$34(40.0)$

$>100$

$13(15.3)$

Number of tumors

1

75 (88.2)

$\geq 2$

$10(11.8)$

Portal vein tumor thrombus

$\begin{array}{lc}\text { Absence } & 76(89.4) \\ \text { Presence } & 9(10.6) \\ \text { BCLC stage } & \\ \text { A } & 70(82.4) \\ \text { B } & 6(7.1) \\ \text { C } & 9(10.6)\end{array}$

Treatment

Surgery

$62(72.9)$

Transcatheter arterial chemoembolization

$17(20.0)$

Thermal ablation

$6(7.1)$
Table 2 Pre-treatment serum cytokine concentrations of 85 patients with hepatocellular carcinoma

\begin{tabular}{lcc}
\hline Cytokine & $\begin{array}{c}\text { Serum concentration, } \\
\text { mean (SD), pg/mL }\end{array}$ & Cutoff value ${ }^{\mathrm{a}}, \mathrm{pg} / \mathrm{mL}$ \\
\hline $\mathrm{IL}-2$ & $0.026(0.139)$ & 0.360 \\
$\mathrm{IL}-4$ & $0.057(0.183)$ & 0.081 \\
$\mathrm{IL}-6$ & $3.366(4.036)$ & 1.435 \\
$\mathrm{IL}-10$ & $2.036(2.466)$ & 1.271 \\
$\mathrm{IFN}-\gamma$ & $0.387(1.341)$ & 0.296 \\
TNF- $\alpha$ & $0.03(0.176)$ & 0.166 \\
\hline
\end{tabular}

${ }^{a}$, the value maximizing the area under the receiver operating characteristics curve and used to define groups in the Cox proportional hazards analysis.

concentrations of each cytokine. Thus, 24 patients had high values for both cytokines, 19 had low values for both cytokines, 24 had high IL-6 concentrations and low AFP concentrations, and 18 had low IL-6 concentrations and high AFP concentrations. OS differed significantly among the four subgroups (Figure 3). Median OS for the whole group was 35.86 months. Median OS for patients with high levels of both cytokines was 9.75 months, which is considerably shorter than that of the other three groups.

\section{Correlation analysis}

Correlation analysis were performed in IL-6 and AFP concentrations in serum samples of 85 HCC patients, and $I L-6$ and AFP mRNA in HCC tumour tissues from The Cancer Genome Atlas (TCGA) database. Concentrations of IL-6 and AFP in serum samples were not correlated $(\mathrm{r}=0.095, \mathrm{P}=0.699$; Figure 4) - a fact confirmed by RNAsequencing data for HCC tumour tissue samples from TCGA database (14) $(r=-0.067, \mathrm{P}=0.197$; Figure 4).

\section{Immunobistochemical expression of IL-6 and CD11b in tumor tissue}

We confirmed the expression pattern of IL-6 in tumor tissues with immunohistochemical staining, which showed that IL-6 was localized predominantly in the tumor stroma, i.e., tumor infiltrating cells. Furthermore, in immunofluorescence staining, IL-6 and CD11b were coexpressed, suggesting that the myeloid cells, not tumor cells, were the primary source of IL-6 (Figure 5). 


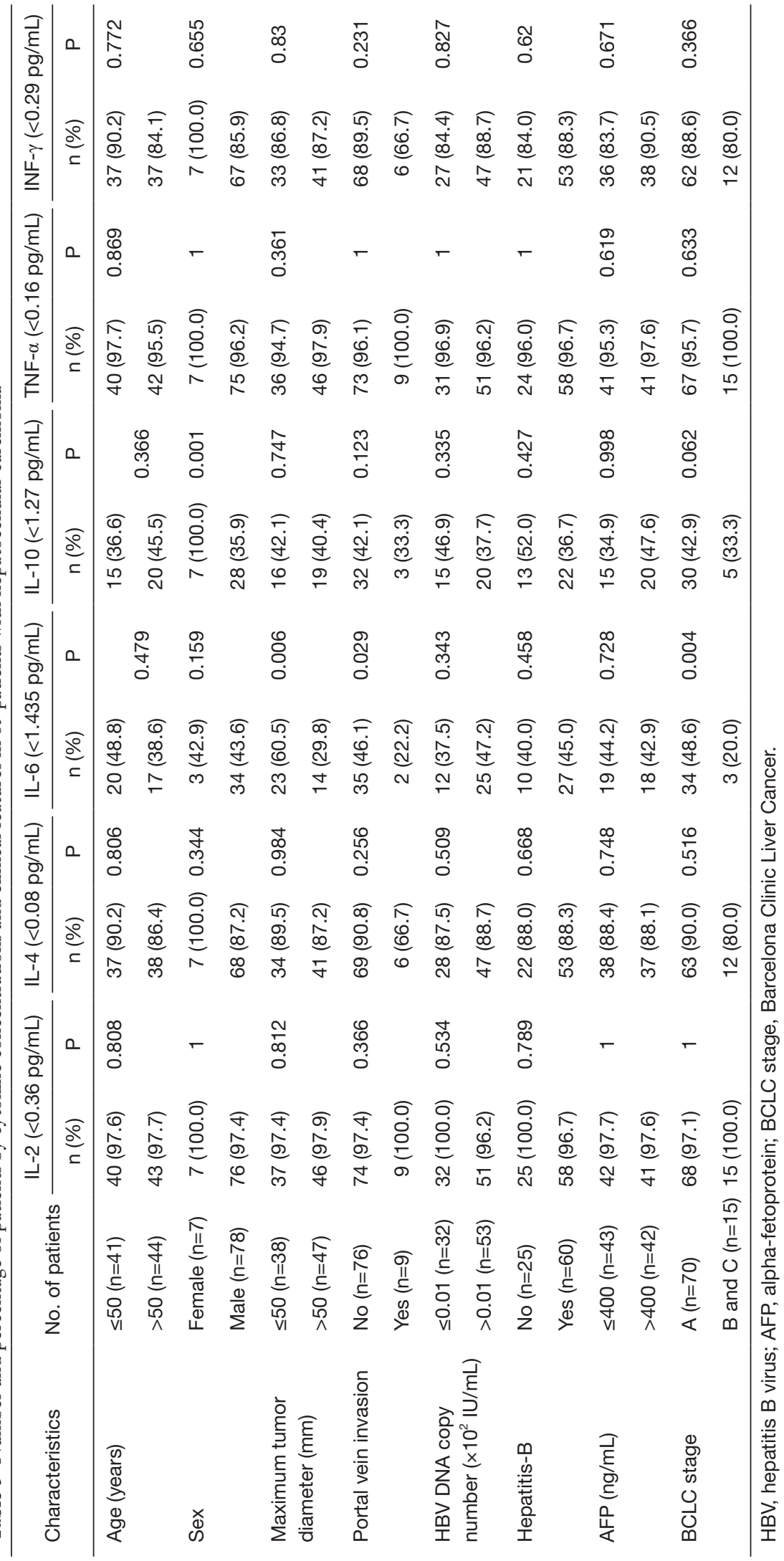




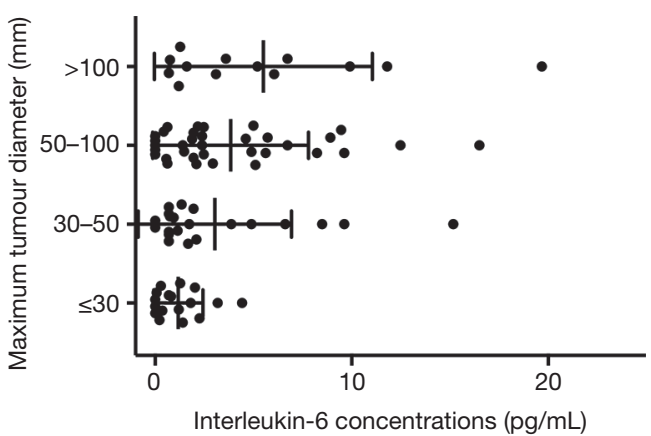

Figure 1 Serum IL-6 concentrations in patients with hepatocellular carcinoma, by maximum tumor diameter. Using Kruskal-Wallis test, serum concentrations of IL-6 differed significantly among the four groups (overall group differences significant at P=0.012); Using MannWhitney $\mathrm{U}$ test, IL-6 in the tumors between $50-100 \mathrm{~mm}$ group and $>100 \mathrm{~mm}$ group were significantly higher than in the tumors $\leq 30 \mathrm{~mm}$ $\operatorname{group}(\mathrm{P}=0.01, \mathrm{P}=0.004)$.
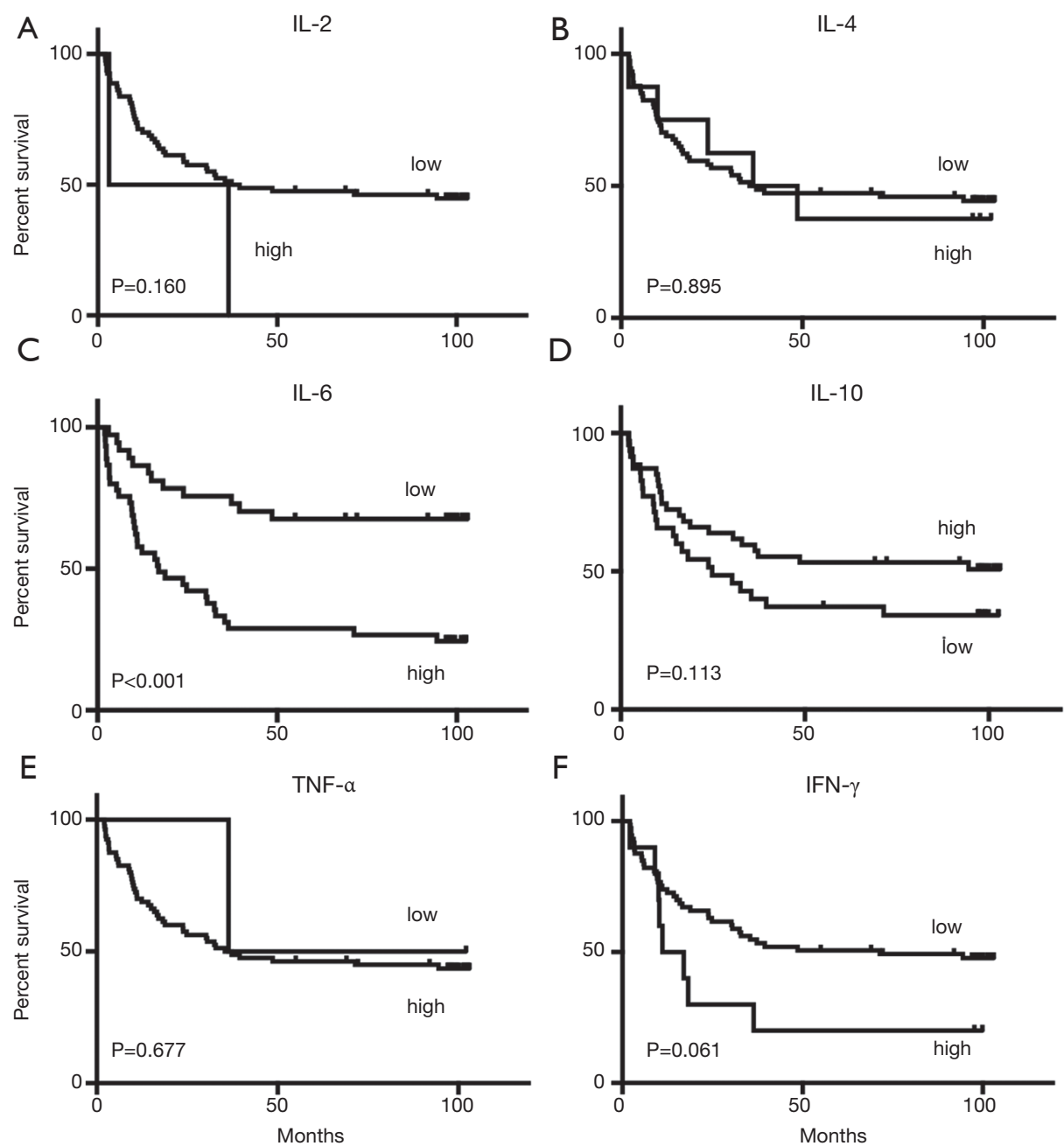

Figure 2 Overall survival in patients with hepatocellular carcinoma. (A) IL-2, (B) IL-4, (C) IL-6, (D) IL-10, (E) TNF- $\alpha$, and (F) IFN- $\gamma$. Kaplan-Meier curves indicating the relationship between months to death after initial treatment were grouped according to cut-off values determined by ROC analysis. ROC, receiver operating characteristic curve. 
Table 4 Univariate and multivariate analysis of the clinical characteristics predicting overall survival in 85 patients with hepatocellular carcinoma

\begin{tabular}{|c|c|c|c|c|}
\hline \multirow{2}{*}{ Characteristic } & \multirow{2}{*}{ Patients (\%) } & \multicolumn{3}{|c|}{ Overall survival } \\
\hline & & $\begin{array}{c}\text { Univariate analysis } \\
\mathrm{P}\end{array}$ & $\mathrm{HR}(95 \% \mathrm{Cl})$ & $\mathrm{P}$ \\
\hline Age $\leq 50$ years & 51 & 0.619 & - & - \\
\hline Sex, male & 91 & 0.115 & - & - \\
\hline Portal vein invasion & 22 & 0.228 & - & - \\
\hline Hepatitis-B & 94 & 0.136 & - & - \\
\hline HBV DNA copy $<0.01 \times 10^{2} \mathrm{IU} / \mathrm{mL}$ & 32 & 0.18 & - & - \\
\hline AFP concentration $\leq 400 \mathrm{ng} / \mathrm{mL}$ & 45 & 0.003 & $2.282(1.217-4.280)$ & 0.01 \\
\hline $\mathrm{IL}-4<0.08 \mathrm{pg} / \mathrm{mL}$ & 88 & 0.895 & - & - \\
\hline $\mathrm{IL}-6<1.40 \mathrm{pg} / \mathrm{mL}$ & 40 & 0.001 & $3.338(1.671-6.666)$ & 0.001 \\
\hline $\mathrm{IL}-10<1.27 \mathrm{pg} / \mathrm{mL}$ & 45 & 0.113 & - & - \\
\hline TNF- $\alpha<0.16 \mathrm{pg} / \mathrm{mL}$ & 97 & 0.677 & - & - \\
\hline $\mathrm{IFN}-\gamma<0.29 \mathrm{pg} / \mathrm{mL}$ & 85 & 0.061 & - & - \\
\hline
\end{tabular}

HBV, hepatitis B virus; AFP, alpha-fetoprotein; BCLC stage, Barcelona Clinic Liver Cancer.

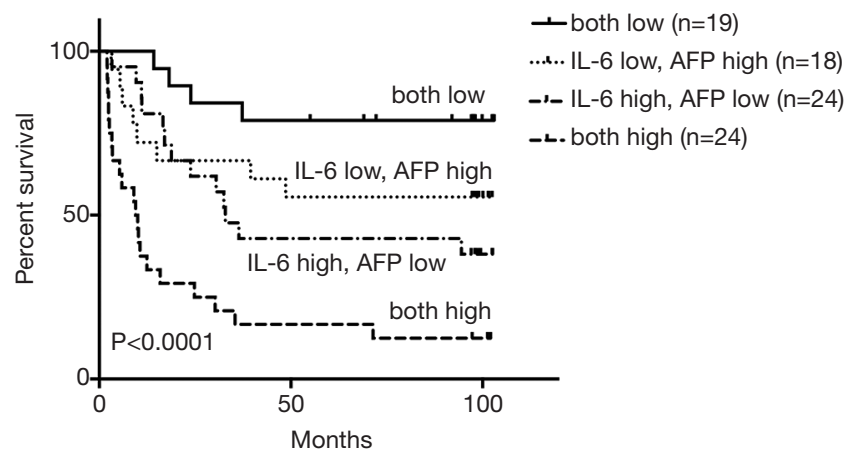

Figure 3 Overall survival in 85 patients with hepatocellular carcinoma, by IL-6 and AFP concentrations. Patients were divided into four groups based on low and high concentrations of each cytokine (AFP, $\leq 400 v s .>400 \mathrm{ng} / \mathrm{mL}$; IL-6, <1.435 vs. $\geq 1.435 \mathrm{ng} / \mathrm{mL}$ ). Among the four groups, patients with high serum concentrations of both cytokines had the worst survival $(\mathrm{P}<0.001)$. AFP, alpha-fetoprotein.

\section{Discussion}

Chronic inflammation is a crucial factor in the development of HCC; the process has been referred to as the "inflammation- fibrosis-cancer axis" (15), which is characterized by the continuous expression of cytokines and recruitment of immune cells into the liver (16). Increased circulatory or intratumoral cytokine concentrations have been reported to be associated with different outcomes in HCC (10,17-19).

In the current study, we measured serum concentrations of six cytokines in 85 patients with HCC. Among them, lower IL-10 and higher IL-6 levels were associated with poorer survival. The tumor-related implications of IL-10 are complex, and both enhancing and inhibitory effects have been observed after IL-10 treatment in different in vivo experimental models (20). We found that lower circulating concentrations of IL-10 predicted, without significance, poorer survival in our patients, but it was not an independent predictor.

Serum IL-6 concentrations are a promising diagnostic marker for HCC (21), and the function of the IL-6 signaling pathway in promoting hepatocarcinogenesis has received increasing attention (22). However, the prognostic value of IL-6 has not been extensively investigated.

Interleukin-6 is an inflammatory cytokine involved in cell proliferation and the acute-phase reaction (21). As a growth-promoting cytokine, IL-6 provides hepatoprotection 

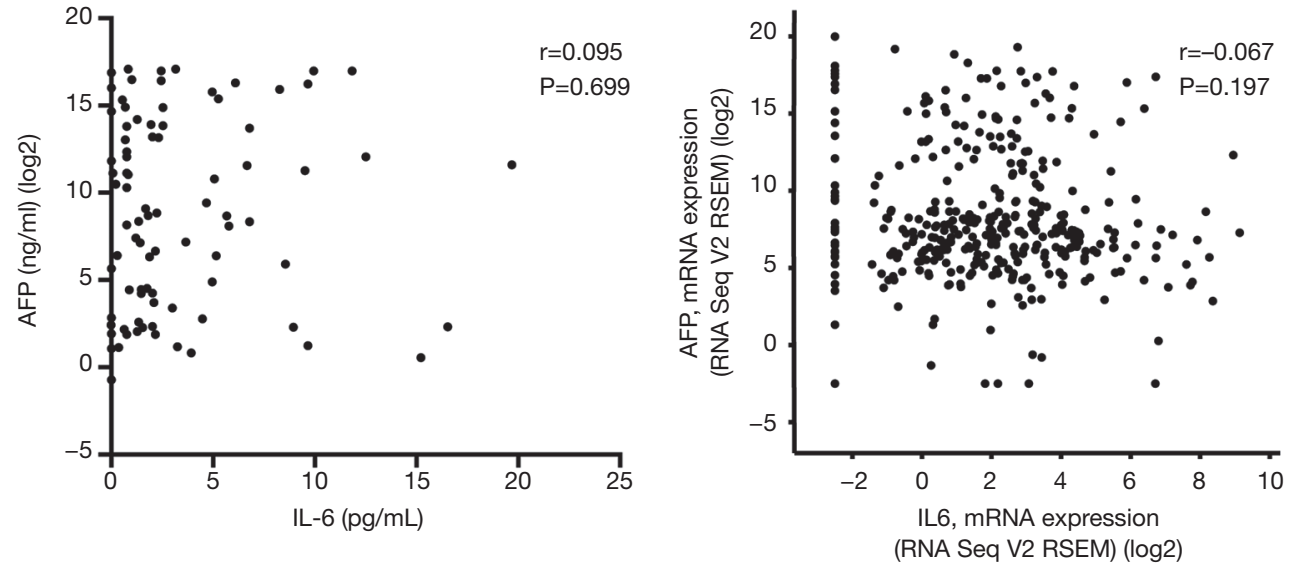

Figure 4 Co-expression analysis of IL-6 and AFP expression in patients with hepatocellular carcinoma. (A) Interleukin-6 and AFP concentrations were not correlated in serum samples of 85 HCC patients ( $\mathrm{r}=0.095 ; \mathrm{P}=0.699$ ). (B) Co-expression analysis shows no correlation between IL-6 and AFP mRNA in tumour tissue samples in the TCGA HCC dataset ( $\mathrm{r}=-0.067$; P=0.197). Levels of target mRNAs were measured using RNA-sequencing in whole tissue section samples and obtained through the cBioportal analysis platform. AFP, alpha-fetoprotein; HCC, hepatocellular carcinoma.

A

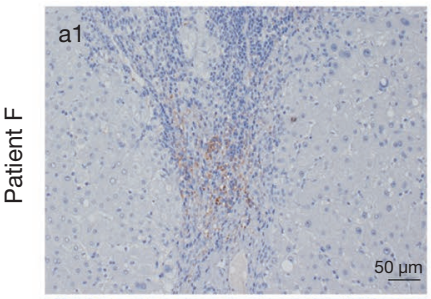

IL-6 (200x)

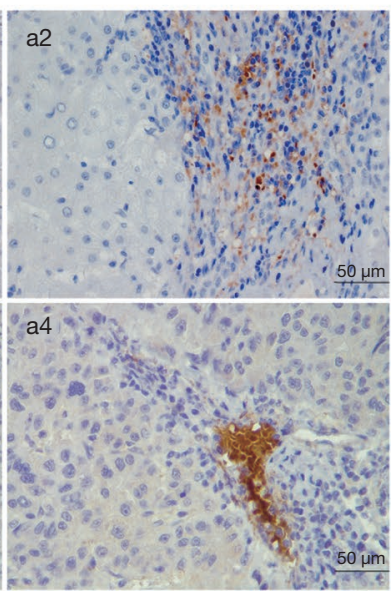

B
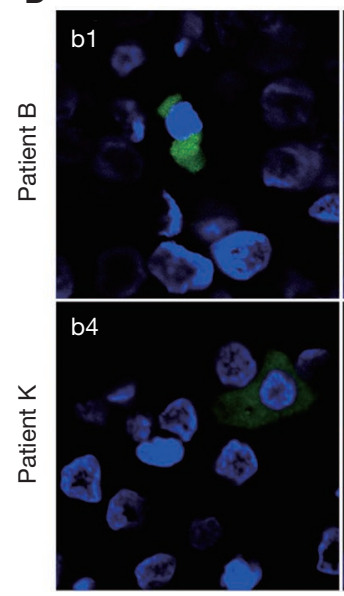

CD11b

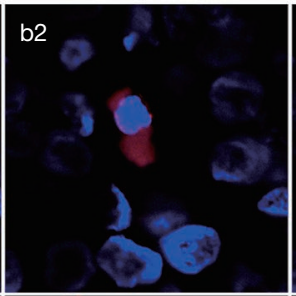

b5

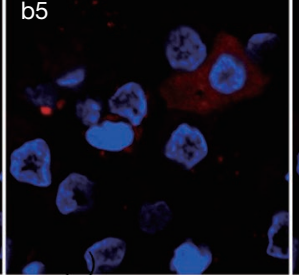

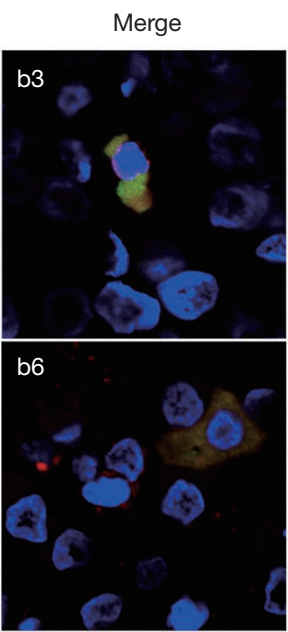

Figure 5 The expression and localization of Interleukin 6 (IL-6) and the cluster of differentiation molecule $11 \mathrm{~b}$ in hepatocellular carcinoma tumor tissue. (A) (a1,a2) IL-6 (brown chromogen) immunohistochemical staining from tumor samples of patient F (200x and 400× magnification); (a3,a4) IL-6 immunohistochemical staining from tumor samples of patient $\mathrm{H}$ (200× and 400× magnification). (B) (b1,b2) Immunofluorescence staining for IL-6 cells (green) and CD11b (red) in tumor sections of patient B with hepatocellular carcinoma (400× magnification); (b4,b5) Immunofluorescence staining for IL-6 cells (green) and CD11b (red) in tumor sections of patient K with hepatocellular carcinoma (400× magnification); (b3,b6) Merge of IL-6 and CD11b in tumor sections of two patients.

by stimulating liver regeneration in liver-injury models (23). However, some evidence indicates that the IL-6 signaling pathway is also important in tumor formation. Serum concentrations of IL-6 have been reported to be elevated in patients with pancreatic ductal adenocarcinoma (24), myeloma (25), non-Hodgkin's lymphoma (26), and
HCC (10). Interleukin-6 signaling occurs through two distinct pathways, termed "classic signaling" and "IL-6 trans-signalling." Mice with impaired IL-6 transsignaling were protected from the development of HCC, indicating a crucial function for this signaling in hepatocellular carcinogenesis (22). Also, IL-6 promotes the 
metastatic potential of HCC by up-regulating osteopontin expression (27). We also found that IL-6 concentrations were associated with portal vein invasion and BCLC stage, thus suggesting the tumorigenic character of IL-6. Our results indicate that IL-6 levels are useful predictors in HCC, a finding consistent with those of Jang et al. (28).

In our study, the expression pattern of IL-6 in HCC tumor tissues localized to tumor stroma, i.e., tumor infiltrating cells. Immunofluorescence staining indicated co-localization of IL-6 and CD11 $\mathrm{b}^{+}$cells and revealed that myeloid cells were one of the sources of IL-6. Hence, the circulating expression of IL-6 may reflect the infiltration of tumor-related immune cells, as well as immune status, in HCC.

AFP is secreted by HCC cells and is associated with the malignant degree of HCC (6). Because IL-6 and AFP are produced independently in HCC and their concentrations are not correlated, these two cytokines might be complementary markers for HCC and thus combining them may have prognostic value. When we divided patients into four subgroups according to their serum concentrations of both IL-6 and AFP, the patients with high serum concentrations of both cytokines had the worst survival $(\mathrm{P}<0.001)$. Further, HCC is a highly malignant tumor with a poor prognosis, and different outcomes have been reported, even among patients with early-stage disease, who are generally thought to have a better prognosis $(29,30)$. Of our 85 patients, 70 (82.4\%) had BCLC stage A cancer, indicating that even patients with early-stage HCC who also have high serum concentrations of both IL-6 and AFP may have a poorer prognosis.

The main limitation of our study was the small sample size. In addition, according to the restriction of our detection method, values below the detection limit could not be analyzed and were considered as zero.

\section{Conclusions}

We believe our data support the conclusion that the concentration of serum IL-6 is an independent prognostic factor for survival in patients with HCC and that its predictive accuracy can be improved by combining it with the AFP concentration. Patients with high concentrations of both IL-6 and AFP may have the most unsatisfactory outcomes.

\section{Acknowledgments}

Funding: The design of the study was supported by National Natural Science Foundation of China (No. 81371652,
No. 81672686, No. 81372883 and No. 81001052); The collection, analysis, and interpretation of data was supported by Guangzhou Science and Technology Program, key projects of collaborative innovation of health medicine (No. 201704020228), Guangzhou Science and Technology Program, key projects of collaborative innovation of production, learning and research (No. 201704020134), Natural Science Foundation of Guangdong Province, China (2015A030313020), Young Talents Key Project of Sun Yatsen University (2015ykzd13) and the Sister Institution Network Fund of MD Anderson Cancer Center.

\section{Footnote}

Conflicts of Interest: All authors have completed the ICMJE uniform disclosure form (available at http://dx.doi. org/10.21037/tcr.2019.08.09). The authors have no conflicts of interest to declare.

Ethical Statement: The authors are accountable for all aspects of the work in ensuring that questions related to the accuracy or integrity of any part of the work are appropriately investigated and resolved. The study was conducted in accordance with the Declaration of Helsinki (as revised in 2013). The study was approved by the Institutional Review Committee of Sun Yat-sen University Cancer Centre in Guangzhou, China (YB2015-018-01). All procedures were performed after obtaining informed consent in accordance with the approved protocol. Written informed consent to the procedure was obtained from patients and their family.

Open Access Statement: This is an Open Access article distributed in accordance with the Creative Commons Attribution-NonCommercial-NoDerivs 4.0 International License (CC BY-NC-ND 4.0), which permits the noncommercial replication and distribution of the article with the strict proviso that no changes or edits are made and the original work is properly cited (including links to both the formal publication through the relevant DOI and the license). See: https://creativecommons.org/licenses/by-nc-nd/4.0/.

\section{References}

1. Torre LA, Bray F, Siegel RL, et al. Global cancer statistics, 2012. CA Cancer J Clin 2015;65:87-108.

2. Au JS, Frenette CT. Management of Hepatocellular Carcinoma: Current Status and Future Directions. Gut 
Liver 2015;9:437-48.

3. Pascual S, Zapater P, Such J, et al. Comparison of staging systems to predict survival in hepatocellular carcinoma. Liver Int 2006;26:673-9.

4. Xu RH, Wei W, Krawczyk M, et al. Circulating tumour DNA methylation markers for diagnosis and prognosis of hepatocellular carcinoma. Nat Mater 2017;16:1155-61.

5. Yamashita T, Forgues $M$, Wang $W$, et al. EpCAM and alphafetoprotein expression defines novel prognostic subtypes of hepatocellular carcinoma. Cancer Res 2008;68:1451-61.

6. Ma WJ, Wang HY, Teng LS. Correlation analysis of preoperative serum alpha-fetoprotein (AFP) level and prognosis of hepatocellular carcinoma (HCC) after hepatectomy. World J Surg Oncol 2013;11:212.

7. Melief CJ, Finn OJ. Cancer immunology. Curr Opin Immunol 2011;23:234-6.

8. Gajewski TF, Schreiber H, Fu YX. Innate and adaptive immune cells in the tumor microenvironment. Nat Immunol 2013;14:1014-22.

9. Pinato DJ, Stebbing J, Ishizuka M, et al. A novel and validated prognostic index in hepatocellular carcinoma: the inflammation based index (IBI). J Hepatol 2012;57:1013-20.

10. Parasole R, Izzo F, Perrone F, et al. Prognostic value of serum biological markers in patients with hepatocellular carcinoma. Clin Cancer Res 2001;7:3504-9.

11. Kubo F, Ueno S, Hiwatashi K, et al. Interleukin 8 in human hepatocellular carcinoma correlates with cancer cell invasion of vessels but not with tumor angiogenesis. Ann Surg Oncol 2005;12:800-7.

12. Liao R, Sun J, Wu H, et al. High expression of IL-17 and IL-17RE associate with poor prognosis of hepatocellular carcinoma. J Exp Clin Cancer Res 2013;32:3.

13. Bruix J, Sherman M, Llovet JM, et al. Clinical management of hepatocellular carcinoma. Conclusions of the Barcelona-2000 EASL conference. European Association for the Study of the Liver. J Hepatol 2001;35:421-30.

14. Gao J, Aksoy BA, Dogrusoz U, et al.Integrative analysis of complex cancer genomics and clinical profiles using the cBioPortal. Sci Signal 2013;6:pl1.

15. Elsharkawy AM, Mann DA. Nuclear factor-kappaB and the hepatic inflammation-fibrosis-cancer axis. Hepatology 2007;46:590-7.

16. Capece D, Fischietti M, Verzella D, et al. The inflammatory microenvironment in hepatocellular carcinoma: a pivotal role for tumor-associated macrophages. Biomed Res Int 2013;2013:187204.

17. Chew V, Tow C, Teo M, et al. Inflammatory tumour microenvironment is associated with superior survival in hepatocellular carcinoma patients. J Hepatol 2010;52:370-9.
18. Tarhuni A, Guyot E, Rufat P, et al. Impact of cytokine gene variants on the prediction and prognosis of hepatocellular carcinoma in patients with cirrhosis. J Hepatol 2014;61:342-50.

19. Trehanpati N, Vyas AK. Immune Regulation by T Regulatory Cells in Hepatitis B Virus-Related Inflammation and Cancer. Scand J Immunol 2017;85:175-81.

20. Dennis KL, Saadalla A, Blatner NR, et al. T-cell Expression of IL10 Is Essential for Tumor Immune Surveillance in the Small Intestine. Cancer Immunol Res 2015;3:806-14.

21. Porta C, De Amici M, Quaglini S, et al. Circulating interleukin-6 as a tumor marker for hepatocellular carcinoma. Ann Oncol 2008;19:353-8.

22. Bergmann J, Müller M, Baumann N, et al. IL-6 transsignaling is essential for the development of hepatocellular carcinoma in mice. Hepatology 2017;65:89-103.

23. Taub R. Hepatoprotection via the IL-6/Stat3 pathway. J Clin Invest 2003;112:978-80.

24. Kim HW, Lee JC, Paik KH, et al. Serum interleukin-6 is associated with pancreatic ductal adenocarcinoma progression pattern. Medicine (Baltimore) 2017;96:e5926.

25. Gupta VA, Matulis SM, Conage-Pough JE, et al. Bone marrow microenvironment-derived signals induce Mcl-1 dependence in multiple myeloma. Blood 2017;129:1969-79.

26. Ozdemir F, Aydin F, Yilmaz M, et al.The effects of IL2, IL-6 and IL-10 levels on prognosis in patients with aggressive Non-Hodgkin's Lymphoma (NHL). J Exp Clin Cancer Res 2004;23:485-8.

27. Wang CQ, Sun HT, Gao XM, et al. Interleukin-6 enhances cancer stemness and promotes metastasis of hepatocellular carcinoma via up-regulating osteopontin expression. Am J Cancer Res 2016;6:1873-89.

28. Jang JW, Oh BS, Kwon JH, et al. Serum interleukin-6 and C-reactive protein as a prognostic indicator in hepatocellular carcinoma. Cytokine 2012;60:686-93.

29. Takayama T, Makuuchi M, Kojiro M, et al. Early hepatocellular carcinoma: pathology, imaging, and therapy. Ann Surg Oncol 2008;15:972-8.

30. Santi V, Trevisani F, Gramenzi A, et al. Semiannual surveillance is superior to annual surveillance for the detection of early hepatocellular carcinoma and patient survival. J Hepatol 2010;53:291-7.

Cite this article as: $\operatorname{Han} \mathrm{X}, \mathrm{Gu} \mathrm{Y}, \mathrm{Li}$ S, Chen M, Cai Q, Huang J. Inflammatory cytokines and alpha-fetoprotein concentrations for predicting survival in patients with hepatocellular carcinoma. Transl Cancer Res 2019;8(5):1680-1689. doi: $10.21037 /$ tcr.2019.08.09 